\title{
The Atlas of human African trypanosomiasis: a contribution to global mapping of neglected tropical diseases
}

Pere P Simarro ${ }^{1 *+}$, Giuliano Cecchi ${ }^{2+}$, Massimo Paone ${ }^{2}$, José R Franco ${ }^{1}$, Abdoulaye Diarra $^{3}$, José A Ruiz ${ }^{4}$, Eric M Fèvre ${ }^{5}$, Fabrice Courtin ${ }^{6}$, Raffaele C Mattioli ${ }^{2}$, Jean G Jannin ${ }^{1}$

\begin{abstract}
Background: Following World Health Assembly resolutions 50.36 in 1997 and 56.7 in 2003, the World Health Organization (WHO) committed itself to supporting human African trypanosomiasis (HAT)-endemic countries in their efforts to remove the disease as a public health problem. Mapping the distribution of HAT in time and space has a pivotal role to play if this objective is to be met. For this reason WHO launched the HAT Atlas initiative, jointly implemented with the Food and Agriculture Organization of the United Nations, in the framework of the Programme Against African Trypanosomosis.

Results: The distribution of HAT is presented for 23 out of 25 sub-Saharan countries having reported on the status of sleeping sickness in the period 2000 - 2009. For the two remaining countries, i.e. Angola and the Democratic Republic of the Congo, data processing is ongoing. Reports by National Sleeping Sickness Control Programmes (NSSCPs), Non-Governmental Organizations (NGOs) and Research Institutes were collated and the relevant epidemiological data were entered in a database, thus incorporating (i) the results of active screening of over 2.2 million people, and (ii) cases detected in health care facilities engaged in passive surveillance. A total of over 42 000 cases of HAT and 6000 different localities were included in the database. Various sources of geographic coordinates were used to locate the villages of epidemiological interest. The resulting average mapping accuracy is estimated at $900 \mathrm{~m}$.

Conclusions: Full involvement of NSSCPs, NGOs and Research Institutes in building the Atlas of HAT contributes to the efficiency of the mapping process and it assures both the quality of the collated information and the accuracy of the outputs. Although efforts are still needed to reduce the number of undetected and unreported cases, the comprehensive, village-level mapping of HAT control activities over a ten-year period ensures a detailed and reliable representation of the known geographic distribution of the disease. Not only does the Atlas serve research and advocacy, but, more importantly, it provides crucial evidence and a valuable tool for making informed decisions to plan and monitor the control of sleeping sickness.
\end{abstract}

\section{Background}

Efficient collection, management and dissemination of information are essential to intervene effectively against neglected tropical diseases and to monitor and evaluate strategies and actions towards their control. However,

\footnotetext{
* Correspondence: SimarroP@who.int

+ Contributed equally

'World Health Organization, Control of Neglected Tropical Diseases, Innovative and Intensified Disease Management, 1211 Geneva 27, Switzerland

Full list of author information is available at the end of the article
}

the neglect suffered by many diseases that affect the world's poorest people manifests itself in many guises, not least in the paucity of reliable information on their incidence and geographic distribution [1,2]. Evidence on the number and location of infections is badly needed to bring these neglected diseases out of the shadow [3] and, most crucially, to tackle them efficiently $[4,5]$.

Disease maps are required for planning, managing and monitoring interventions across the whole spectrum of neglected tropical diseases. For conditions such as helminthiases and trachoma, against which safe and 
affordable drugs are available, baseline maps of endemicity are used to plan mass drug administration (MDA) campaigns [6-8]. As campaigns progress, spatially-explicit data enable implementation to be monitored and ultimately contribute to assessing the degree of success of the initiatives [9]. Geo-spatial information also plays a role in the post-MDA phase when surveillance aims at providing early-warning of the possible disease resurgence or reintroduction in freed areas.

A different group of diseases such as human African trypanosomiasis (HAT), Chagas disease and leishmaniasis, are characterized by the limited availability of safe and cost-effective control tools. This group includes infections of complex epidemiology, which, if untreated, can result in very high death rates. Strategies to control them hinge on early diagnosis and treatment, as well as on vector control. Accurate, spatially-explicit information is essential to target, monitor and evaluate interventions against these challenging and deadly diseases [10-12].

Geo-referenced data are also crucial when control strategies are successful and elimination or eradication of a disease can be contemplated. This is exemplified by the "Dracunculiasis Eradication Program", wherein village-level information on disease occurrence and programme implementation is routinely collected to monitor progress towards the programme's ultimate goal [13].

Disease distribution maps are also required if accurate estimates of the population at risk and of the burden of diseases are to be made. The issue of the most appropriate metrics to estimate the burden is subject of debate [14,15], but there is increasing recognition that the burden of neglected tropical diseases still needs to be fully appreciated [16] and that more detailed and reliable data on their incidence and impacts need to be collected [17-19].

The present paper focuses on HAT, also known as sleeping sickness, whose etiological agents are tsetsetransmitted protozoa of the species Trypanosoma brucei. Two sub-species are responsible for syndromes of markedly different epidemiology and geographical range. T. b. gambiense causes the chronic, anthroponotic form found in Western and Central Africa. Infection with T. $b$. rhodesiense results in the acute, zoonotic form of Eastern and Southern Africa. Both forms are considered fatal if untreated. No vaccine against HAT is available, and the toxicity of existing drugs precludes the adoption of control strategies based on preventive chemotherapy. As a result, the keystones of interventions against sleeping sickness are active and passive case-finding followed by treatment, vector control and animal reservoir management.

Following World Health Assembly resolutions 50.36 in 1997 [20] and 56.7 in 2003 [21], the World Health
Organization (WHO) committed itself to supporting HAT-endemic countries in their efforts to remove the disease as a public health problem. Mapping disease distribution in time and space has a pivotal role to play if this objective is to be met.

Partly because of the focal nature of sleeping sickness geography, HAT control has always been intimately entwined with disease mapping [22]. For example, as early as 1903, detailed maps of HAT distribution were published in Uganda [23] and foci were mapped in Western and Central Africa in the period 1908-1910 $[24,25]$. In the last decade, mapping and geo-positioning have become much more accessible with the widespread diffusion of Geographic Information Systems (GIS) and satellite-aided positioning systems (e.g. the Global Positioning System (GPS)). These technical tools are at the basis of the systematic approach to sleeping sickness mapping embodied in the Atlas of HAT, the first attempt ever to geo-reference at the village level all sleeping sickness cases reported from affected countries [26]. Underpinning this initiative are the commitment of WHO and the Food and Agriculture Organization of the United Nations (FAO), the institutional umbrella provided by the Programme against African Trypanosomosis (PAAT) and the crucial input of National Sleeping Sickness Control Programmes (NSSCPs), NonGovernmental Organizations (NGOs) and Research Institutes.

This paper presents the process of building the Atlas of HAT for the period 2000-2009. The distribution of HAT is presented for 23 out of 25 sub-Saharan countries having reported on the status of sleeping sickness during the last ten years: Benin, Burkina Faso, Cameroon, Central African Republic, Chad, Congo, Côte d'Ivoire, Equatorial Guinea, Gabon, Ghana, Guinea, Kenya, Malawi, Mali, Mozambique, Nigeria, Rwanda, Sudan, Togo, Uganda, United Republic of Tanzania, Zambia and Zimbabwe. Work is in progress to process data from the two remaining countries having reported on HAT in the study period: Angola and the Democratic Republic of the Congo (DRC).

The presented maps are a fundamental milestone in the process of building the continental Atlas of HAT. The unprecedented accuracy and comprehensiveness of the Atlas are to make it an essential tool for disease control, research and advocacy.

\section{Methods}

The central feature of the Atlas of HAT is the mapping at village level of all new cases of HAT reported during a ten-year period (2000-2009, see Table 1 for T. b. gambiense and Table 2 for T. $b$. rhodesiense).

In addition to the new HAT reported cases, results of all active case-finding surveys are also included in the 
Table 1 T. b. gambiense Sleeping Sickness: new cases reported between 2000 and 2009

\begin{tabular}{|c|c|c|c|c|c|c|c|c|c|c|c|}
\hline Country & 2000 & 2001 & 2002 & 2003 & 2004 & 2005 & 2006 & 2007 & 2008 & 2009 & Total \\
\hline Angola & 4,546 & 4,577 & 3,621 & 3,115 & 2,280 & 1,727 & 1,105 & 648 & 517 & 247 & 22,383 \\
\hline Benin $^{1}$ & 0 & 0 & 0 & 0 & 0 & 0 & 0 & 0 & 0 & 0 & 0 \\
\hline Burkina Faso ${ }^{2}$ & 0 & 0 & 0 & 0 & 0 & 0 & 0 & 0 & 0 & 0 & 0 \\
\hline Cameroon $^{3}$ & 27 & 14 & 32 & 33 & 17 & 3 & 15 & 7 & 13 & 24 & 185 \\
\hline Central African Republic ${ }^{4}$ & 988 & 718 & 572 & 539 & 738 & 666 & 460 & 654 & 1,194 & 1,054 & 7,583 \\
\hline Chad & 153 & 138 & 715 & 222 & 483 & 190 & 276 & 97 & 196 & 510 & 2,980 \\
\hline Congo $^{5}$ & 111 & 894 & 1,005 & 717 & 873 & 398 & 300 & 189 & 182 & 87 & 4,756 \\
\hline Côte d'Ivoire ${ }^{6}$ & 188 & 92 & 97 & 68 & 74 & 42 & 29 & 13 & 14 & 8 & 625 \\
\hline Democratic Republic of the Congo & 16,975 & 17,322 & 13,853 & 11,481 & 10,369 & 10,269 & 8,023 & 8,162 & 7,326 & 7,183 & 110,963 \\
\hline Equatorial Guinea & 16 & 17 & 32 & 23 & 22 & 17 & 13 & 15 & 11 & 7 & 173 \\
\hline Gabon $^{7}$ & 45 & 30 & 26 & 26 & 49 & 53 & 31 & 30 & 24 & 14 & 328 \\
\hline Gambia & - & - & - & - & - & - & - & - & - & - & 0 \\
\hline Ghana & 1 & 0 & 0 & 0 & 0 & 0 & 0 & 0 & 0 & 0 & 1 \\
\hline Guinea $^{8}$ & 52 & 72 & 132 & 130 & 95 & 94 & 48 & 69 & 90 & 79 & 861 \\
\hline Guinea-Bissau & - & - & - & - & - & - & - & - & - & - & 0 \\
\hline Liberia & - & - & - & - & - & - & - & - & - & - & 0 \\
\hline Malii & 0 & 0 & 0 & 0 & 0 & 0 & 0 & 0 & 0 & 0 & 0 \\
\hline Niger & - & - & - & - & - & - & - & - & - & - & 0 \\
\hline Nigeria & 14 & 14 & 26 & 31 & 10 & 21 & 3 & 0 & 0 & 0 & 119 \\
\hline Senegal & - & - & - & - & - & - & - & - & - & - & 0 \\
\hline Sierra Leone & - & - & - & - & - & - & - & - & - & - & 0 \\
\hline Sudan ${ }^{10}$ & 1,801 & 1,919 & 3,121 & 3,061 & 1,742 & 1,853 & 789 & 469 & 623 & 376 & 15,754 \\
\hline Togo & 0 & 0 & 0 & 0 & 0 & 0 & 0 & 0 & 0 & 0 & 0 \\
\hline Uganda $^{11}$ & 948 & 310 & 604 & 517 & 378 & 311 & 290 & 120 & 198 & 99 & 3,775 \\
\hline Total reported & 25,865 & 26,117 & 23,836 & 19,963 & 17,130 & 15,644 & 11,382 & 10,473 & 10,388 & 9,688 & 170,486 \\
\hline
\end{tabular}

"-", no data reported.

" 0 ", no cases reported despite active and passive surveillance is in place.

For countries in italics (Angola and Democratic Republic of the Congo) data processing is still in progress.

1 Data for Benin include revisions of previously published figures [27,28], Suspected cases reported between 2000 and 2003 were not confirmed by verification and follow-up missions [29].

${ }^{2}$ Data for Burkina Faso include revisions of previously published figures [27,28]. Cases reported from Burkina Faso between 2000 and 2004 have been labelled as "transboundary" and subsequently attributed to Côte d'Ivoire, the country of infection [29].

${ }^{3}$ Previously published number of cases from Cameroon in $2001[27,28]$ has been revised to include one case "exported" to Germany.

${ }^{4}$ Data for Central African Republic include revisions of previously published figures for the years from 2001 to 2003 [27,28]. Revisions arose from a re-assessment of the epidemiological data, including ward and laboratory books, reports of active case-finding surveys and "exported" cases.

${ }^{5}$ Data for Congo include revisions of previously published figures for the years 2003 and 2004 [27,28]. Revised figures include cases diagnosed by NGOs.

${ }^{6}$ Data for Côte d'Ivoire include revisions of previously published figures for the years 2000 to 2005 [27,28]. Revisions arose from a re-assessment of the epidemiological data, including ward and laboratory books, reports of active case-finding surveys and "transboundary" cases diagnosed in Burkina Faso.

${ }^{7}$ Previously published number of cases from Gabon in 2002 and 2004 [27,28] have been revised to include cases "exported" to France and Italy.

${ }^{8}$ Data for Guinea include revisions of previously published figures for the years from 2002 to 2004 [27,28]. Revisions arose from a re-assessment of the epidemiological data, including ward and laboratory books, reports of active case-finding surveys and "exported" cases.

${ }^{9}$ Data for Mali include revisions of previously published figures [27,28]. Suspected cases reported between 2000 and 2002 were not confirmed by verification and follow-up missions [29].

${ }^{10}$ Data for Sudan include revisions of previously published figures for the years 2000 to $2006[27,28]$. Revisions arose from the re-assessment of transboundary cases and the inclusion of exported cases.

${ }^{11}$ Data for Uganda include revisions of previously published figures for the years 2000 to $2006[27,28]$. Revisions arose from the re-assessment of transboundary cases and the inclusion of exported cases.

Atlas, even if no case was detected, as this provides important information on the populations screened and the epidemiological status of historical transmission areas.

Data from both active and passive surveillance are analyzed and imported into a single database, where a selected set of ancillary data are also recorded if available (i.e. number of people screened, number of people living in screened localities, disease stage).

Since the methodology used to build the HAT database has been described in detail elsewhere [26], this section elaborates only on those key methodological aspects that have repercussions on mapping accuracy and on the epidemiological interpretation of the outputs. 
Table 2 T. b. rhodesiense Sleeping Sickness: new cases reported between 2000 and 2009

\begin{tabular}{|c|c|c|c|c|c|c|c|c|c|c|c|}
\hline Country & 2000 & 2001 & 2002 & 2003 & 2004 & 2005 & 2006 & 2007 & 2008 & 2009 & Total \\
\hline Botswana & - & - & - & - & - & - & - & - & - & - & - \\
\hline Burundi & - & - & - & - & - & - & - & - & - & - & - \\
\hline Ethiopia & - & - & - & - & - & - & - & - & - & - & - \\
\hline Kenya ${ }^{1}$ & 15 & 10 & 11 & 0 & 0 & 0 & 1 & 0 & 0 & 1 & 38 \\
\hline Malawi ${ }^{2}$ & 35 & 38 & 43 & 70 & 48 & 41 & 58 & 50 & 49 & 39 & 471 \\
\hline Mozambique & - & - & 1 & - & 1 & - & - & - & - & - & 2 \\
\hline Namibia & - & - & - & - & - & - & - & - & - & - & - \\
\hline Rwanda $^{3}$ & 0 & 0 & 0 & 0 & 0 & 0 & 0 & 0 & 0 & 0 & 0 \\
\hline Swaziland & - & - & - & - & - & - & - & - & - & - & - \\
\hline Uganda $^{4}$ & 300 & 426 & 329 & 338 & 335 & 473 & 261 & 119 & 138 & 129 & 2,848 \\
\hline United Republic of Tanzania ${ }^{5}$ & 350 & 277 & 228 & 113 & 159 & 186 & 127 & 126 & 59 & 14 & 1,639 \\
\hline Zambia $^{6}$ & 9 & 4 & 5 & 15 & 9 & 7 & 6 & 10 & 13 & 4 & 82 \\
\hline Zimbabwe ${ }^{7}$ & 0 & 0 & 0 & 0 & 0 & 3 & 0 & 0 & 0 & 3 & 6 \\
\hline Total & 709 & 755 & 617 & 536 & 552 & 710 & 453 & 305 & 259 & 190 & 5,086 \\
\hline
\end{tabular}

"-", no data reported.

" 0 ", no cases reported despite passive surveillance is in place.

${ }^{1}$ Data for Kenya include revisions of previously published figures for the years 2000 to 2002 [27,28]. Revised figures include "transboundary" cases diagnosed in Uganda.

${ }^{2}$ The previously published figure for Malawi in $2004[27,28]$ has been revised. The revised figure includes a case "exported" from Malawi to United Kingdom.

${ }^{3}$ Data for Rwanda include revisions of previously published figures for the years 2001 and 2004 [27,28], which had been affected by an error in the yearly reports to WHO (Data verified through a joint assessment by the Rwandan Ministry of Health and WHO).

${ }^{4}$ Data for the Uganda include revisions of previously published figures for the year 2000 and the years from 2002 to 2006 [27,28]. Revisions arose from a reassessment of the epidemiological data, including ward and laboratory books. "Transboundary" cases from Kenya have also been considered.

${ }^{5}$ Data for the United Republic of Tanzania include revisions of previously published figures for the years from 2000 to 2006 [27,28]. The revised includes all cases "exported" from the United Republic of Tanzania to other countries.

${ }^{6}$ Data for Zambia include revisions of previously published figures for the years 2001 and 2006 [27,28], which had been affected by an error in the yearly reports to WHO (Data verified through a joint assessment by the Zambian Ministry of Health and WHO). "Exported" cases have also been included.

${ }^{7}$ The previously published figure for Zimbabwe in $2005[27,28]$ has been revised following a re-assessment of epidemiological reports.

\section{Where to map HAT cases}

Data on HAT cases detected by active case-finding surveys are collected by mobile teams visiting villages in transmission areas. As a rule, people are tested in their village of residence, which therefore is used as the reference for mapping. However, participants in a massscreening event carried out in a given village may also comprise people coming from neighbouring settlements, normally located only a few kilometres away. If these settlements of origin are explicitly mentioned in the mission report, it is possible to refer the relevant individuals back to their exact place of residence, thus more accurately reflecting in the Atlas the epidemiological milieu in which they live. If information on the exact place of residence is not available, cases are mapped in the village where the screening took place.

For HAT cases detected by passive surveillance in referral healthcare facilities, the patient's village of residence is normally recorded in laboratory and ward register books and thus it can be used for mapping. Therefore, the patient's village of residence constitutes the basic mapping unit for both actively and passively reported cases.

Hospital records pointing to villages of residence located far from known endemic areas are investigated on a case-by-case basis, with a view towards ascertaining the accuracy of the recorded information and clarifying its epidemiological significance. Indeed, cultural factors and communication difficulties may lead the patient to declare, or the doctor or technician to record, the patient's place of birth or the place of origin of their family as their village of residence. The mapping process often allows these issues to be identified.

More generally, careful verification is carried out for all outliers (e.g. places of residence that are inconsistent with the catchment area of the reporting healthcare structure, cases falling outside tsetse-infested areas, etc). Cases originating from areas with no reported history of HAT undergo special scrutiny, as they could point to new transmission zones requiring in-depth field investigation.

Other challenges to HAT mapping are posed by refugees and internally displaced people who are mapped in their camps if their village of residence is unknown; soldiers are mapped in the localities where they are stationed. Mapping of other categories of migrating workers, for whom establishing the most meaningful place of residence is a demanding endeavour, is guided by knowledge of the local epidemiology of the disease and perspectives given by the long field-experience of NSSCPs staff. 
Importantly, notes included in the HAT database provide details on all cases that required ad-hoc investigation, so as to make the interpretation process transparent to users.

HAT cases are also occasionally diagnosed in a country that is different from the country where the patient contracted the infection. This is relatively frequent between HAT-endemic countries as a result of transboundary foci. To capture these cases the Atlas presents the special category "transboundary case". The corresponding individuals are mapped in the village of residence in the country of infection and flagged accordingly as "transboundary cases". The place and country of diagnosis are also recorded in the notes of the database with a view to understanding population movements within transboundary foci.

HAT infections are also diagnosed in countries that are not endemic for HAT, including countries outside Africa, mostly in migrants and tourists who come from or have visited endemic areas. The category of "exported case" has been created in the HAT Atlas to reflect this phenomenon. In the maps presented in this paper, exported cases are associated to the probable place of infection; in the case of tourists, this is most often represented by the centroid of a national park or another wildlife management area. The importing countries, as well as the places of diagnoses, are also recorded in the notes of the database, which will allow a "World map" of HAT exported cases to be generated.

\section{How to georeference HAT cases}

Once the village to be mapped has been determined, its geographic coordinates must be measured or estimated. A procedure was devised whereby coordinates are first sought in the epidemiological reports [26]. When not available there, coordinates are searched for in gazetteers (i.e. databases of named locations). These two sources enable the majority of villages to be mapped. As a third option, other sources of geographic information can be used, including paper and digital maps, as well as hand-drawn, out-of-scale sketches of the endemic areas that may be available in the epidemiological reports.

When all the available data sources have been exhausted, a limited but non-negligible number of settlements, especially the smaller or temporary, often remain unmapped, thus calling for further investigation. Direct consultation with first-line field workers of the NSSCPs (either via face-to-face interviews, cell-phone or e-mail) has proved the most speedy and cost-effective manner to locate - most frequently in relation to other known locations - hundreds of these small and often remote settlements.

\section{Mapping accuracy}

The various sources of geographic information used to build the HAT Atlas are characterized by different levels of accuracy. To estimate the overall spatial accuracy of the resulting maps we classified mapped locations into four broad categories of accuracy: very high, high, moderate and low.

The first category, i.e. "very high accuracy", includes locations whose coordinates were derived from GPS measurements carried out by field teams in charge of HAT reporting. These measurements can be affected by an error as little as a few metres, but we conservatively estimated an average error of $50 \mathrm{~m}$. Certain coordinates obtained from gazetteers are also included in the first category of accuracy, but only if no rounding of the coordinates was carried out (i.e. coordinates must be available from gazetteers in full, as degrees, minutes and seconds, or down to the $4^{\text {th }}$ decimal place if decimal degrees notation was used).

The second category ("high accuracy") includes all those cases where coordinates obtained from gazetteers have, for some reason, been rounded (or truncated) at the source. For example, in the GEOnet Names Server database, which provides the baseline for many, if not all, of the available gazetteers [30], more than half of the coordinates for Africa are rounded to the nearest minute, which results in errors of up to $928 \mathrm{~m}$. For this second category we therefore estimated an average error of $500 \mathrm{~m}$.

"Medium" and "low" accuracy refer to coordinates that were estimated in an approximate manner, i.e. by using digital and paper maps, out-of-scale sketches of survey areas, as well as qualitative information received from field-workers. The difference between the two categories lies in the detail of the qualitative information they are based upon. For example, "medium" accuracy may derive from indications such as "the village to be mapped is located at 1 kilometre from village $\times$, along the road to village $y^{\prime \prime}$, with the obvious assumption that the position of villages $x$ and $y$ and the road connecting them be known. By contrast, "low" accuracy may result from less precise indications, such as "village $\times$ is located between village $y$ and village $z$, along the river $w$ ". We estimate an average accuracy of $2,500 \mathrm{~m}$ and $5,000 \mathrm{~m}$ for the categories "medium" and "low" respectively.

\section{Definition of HAT case}

The Atlas aims to map all new HAT cases reported by affected countries. As a rule, NSSCPs consider parasitological confirmation (i.e. direct observation of trypanosomes in bodily fluids) as mandatory for HAT diagnosis. However, under certain circumstances, NSSCPs consider a seropositive individual as affected, even in the absence of parasitological confirmation. This occurs more frequently 
in T. b. gambiense highly endemic or epidemic areas, where the likelihood of false positives in serological tests is deemed lower. For the Atlas of HAT we simply follow national rules for the definition of HAT cases. However, in the database note is taken of all the instances when NSSCPs have included seropositives without parasitological confirmation in the totality of HAT cases.

\section{Results}

\section{Mapping of HAT}

As we write, mapping in 23 countries out of the 25 that reported on HAT occurrence in the period 2000-2009 has been completed (Figure 1). Data processing is considered complete when all available data sources for the study period have been analysed and entered in the database. Approximately 1500 unpublished files, including epidemiological reports, maps, databases and spreadsheets, have been analyzed for the 23 study countries, thus incorporating (i) the results of active screening of over 2.2 million people, and (ii) cases detected in health care facilities engaged in passive surveillance. A total of over 42000 cases of HAT and 6000 different localities have been included in the database. Work is in progress to process data from the 2 remaining countries having reported the largest burden of HAT cases in the study period: Angola and DRC (represented with a striped pattern in Figure 1). Eight countries listed as endemic have provided no report on the HAT situation in 20002009: Burundi, Ethiopia, Gambia, Guinea-Bissau, Liberia, Niger, Senegal and Sierra Leone (represented with a yellow chequerboard pattern in Figure 1). Efforts should be made to clarify the epidemiological status of HAT in these eight countries. In Botswana, Namibia and Swaziland (represented with a green chequerboard pattern in Figure 1), it is suggested that transmission of sleeping sickness may have been interrupted because of

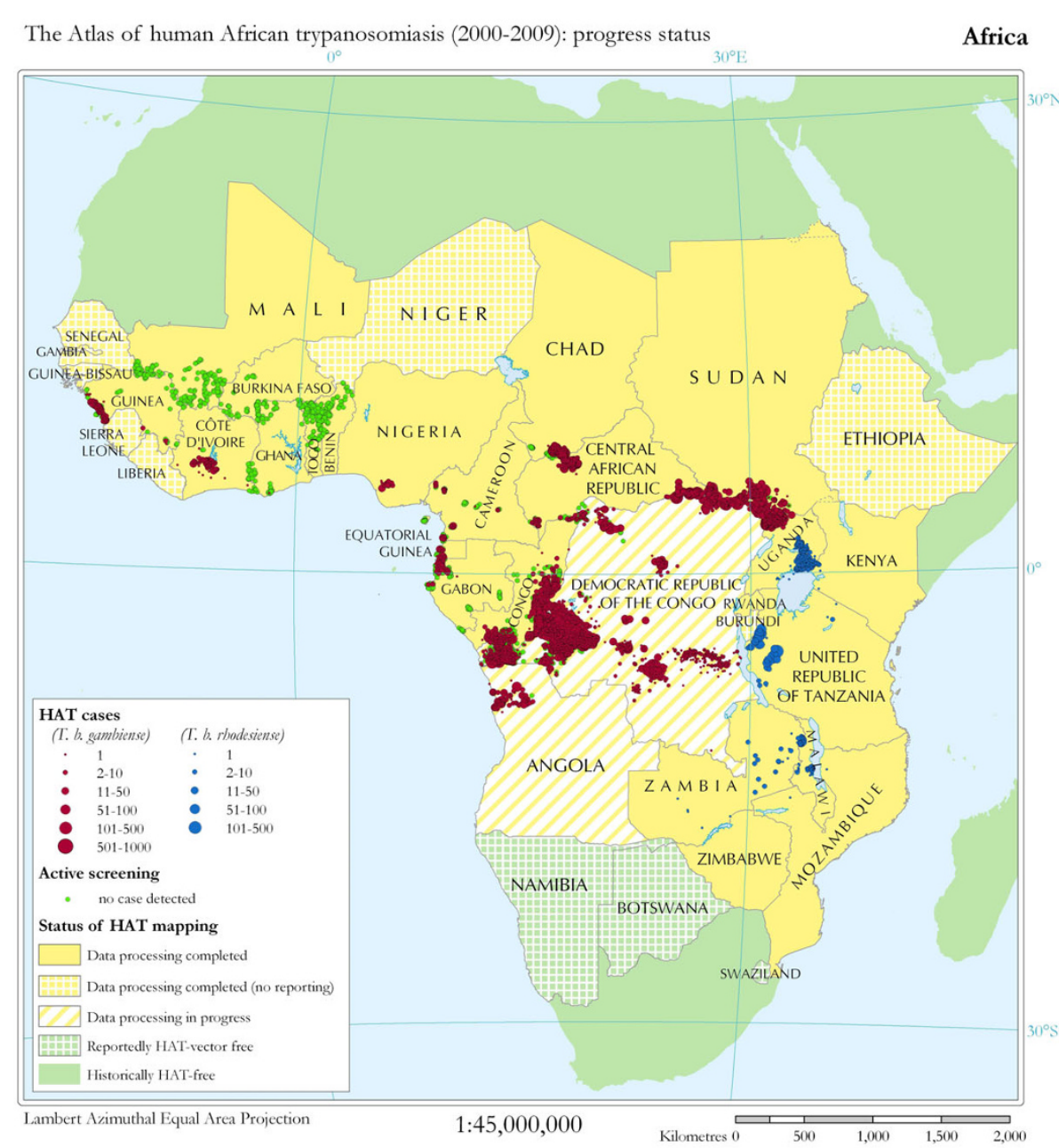

Figure 1 The Atlas of human African trypanosomiasis: progress status. For each country, data processing is considered complete when all available data sources for the study period (2000-2009) have been analysed and included in the HAT database. 
successful tsetse elimination campaigns recently implemented in Botswana and Namibia [31-33], as well as evidence indicating that Glossina austeni - a species not involved in HAT transmission [34,35] - is currently the only species of tsetse fly present in Swaziland [36].

To date, not all cases reported from completed countries could be mapped. Table 3 shows that approximately 10 percent of cases could not be geo-referenced at the village level yet, although the focus of origin is known. The majority of gaps in mapped cases originate from passive surveillance, as the number of sleeping sickness cases may be reported as focus-level aggregates, without specific reference to the patients' village of residence. Despite actions to visit the source for more detailed data, it occurs that the necessary village-level information may have been permanently lost, especially because of the violent conflicts that ravaged numerous HAT endemic areas in recent years.

\section{HAT distribution}

Present results of the HAT Atlas initiative are shown in Figure 2, Figure 3 and Figure 4, which represent the distribution of both forms of HAT in 23 countries.

\section{Western Africa}

In Western Africa (Figure 2), three countries are still reporting significant levels of disease incidence: Guinea, Côte d'Ivoire and Nigeria. In Guinea, HAT cases originate from the mangrove biotope (Guinée Maritime) where people expose themselves to the risk of infection when fishing, growing rice and collecting firewood and salt. This region includes the foci of Boffa, Dubréka and Forécariah, the latter close to the border with Sierra Leone. The presence of the same mangrove biotope across this porous border suggests that the disease might also be present in the territory of Sierra Leone, even though no case is reported from this country. However, an exploratory mission carried out in early 2010 in 24 villages of Sierra Leone close to the Guinean border (results included in Figure 2) failed to find evidence of HAT [37]. In Guinea, HAT cases are also reported from the forest biotope (Guinée Forestière), namely from N'zérékoré and Guéckédou foci.

In Côte d'Ivoire, transmission is reported among workers of cocoa and coffee plantations in the Centrewest of the country that comprises the foci of Daloa (Haut-Sassandra Region), Sinfra and Bonon (Marahoué

Table 3 Progress status of mapping for HAT cases and geographic locations (period 2000 - 2009)

\begin{tabular}{|c|c|c|c|c|}
\hline \multirow[t]{2}{*}{ Country } & \multicolumn{2}{|c|}{ HAT cases } & \multicolumn{2}{|c|}{ Geographic locations $^{1}$} \\
\hline & Reported (number) & Mapped (\%) & Reported (number) & Mapped (\%) \\
\hline Benin & 0 & - & 194 & 100.0 \\
\hline Burkina Faso & 0 & - & 32 & 100.0 \\
\hline Cameroon & 185 & 100.0 & 111 & 100.0 \\
\hline Central African Republic & 7,583 & 97.1 & 420 & 94.5 \\
\hline Chad & 2,980 & 82.7 & 230 & 89.6 \\
\hline Congo & 4,756 & 96.1 & 889 & 98.3 \\
\hline Côte d'Ivoire & 625 & 91.0 & 237 & 96.6 \\
\hline Equatorial Guinea & 173 & 100.0 & 111 & 100.0 \\
\hline Gabon & 328 & 100.0 & 237 & 100.0 \\
\hline Ghana & 1 & 100.0 & 99 & 97.0 \\
\hline Guinea & 861 & 95.7 & 290 & 91.7 \\
\hline Kenya & 38 & 100.0 & 27 & 100.0 \\
\hline Malawi & 471 & 82.0 & 125 & 84.8 \\
\hline Mali & 0 & - & 244 & 84.8 \\
\hline Mozambique & 2 & 100.0 & 2 & 100.0 \\
\hline Nigeria & 119 & 100.0 & 23 & 100.0 \\
\hline Rwanda & 0 & - & 0 & - \\
\hline Sudan & 15,754 & 82.4 & 692 & 88.3 \\
\hline Togo & 0 & - & 90 & 100.0 \\
\hline Uganda & 6,623 & 98,1 & 1,902 & 85,2 \\
\hline United Republic of Tanzania & 1,639 & 93.5 & 45 & 88.9 \\
\hline Zambia & 82 & 100.0 & 29 & 100.0 \\
\hline Zimbabwe & 6 & 100.0 & 5 & 100.0 \\
\hline TOTAL & 42,226 & 90.3 & 6,035 & 91,4 \\
\hline
\end{tabular}

${ }^{1}$ Geographic locations also include those where active screening was carried out but no case was detected. 


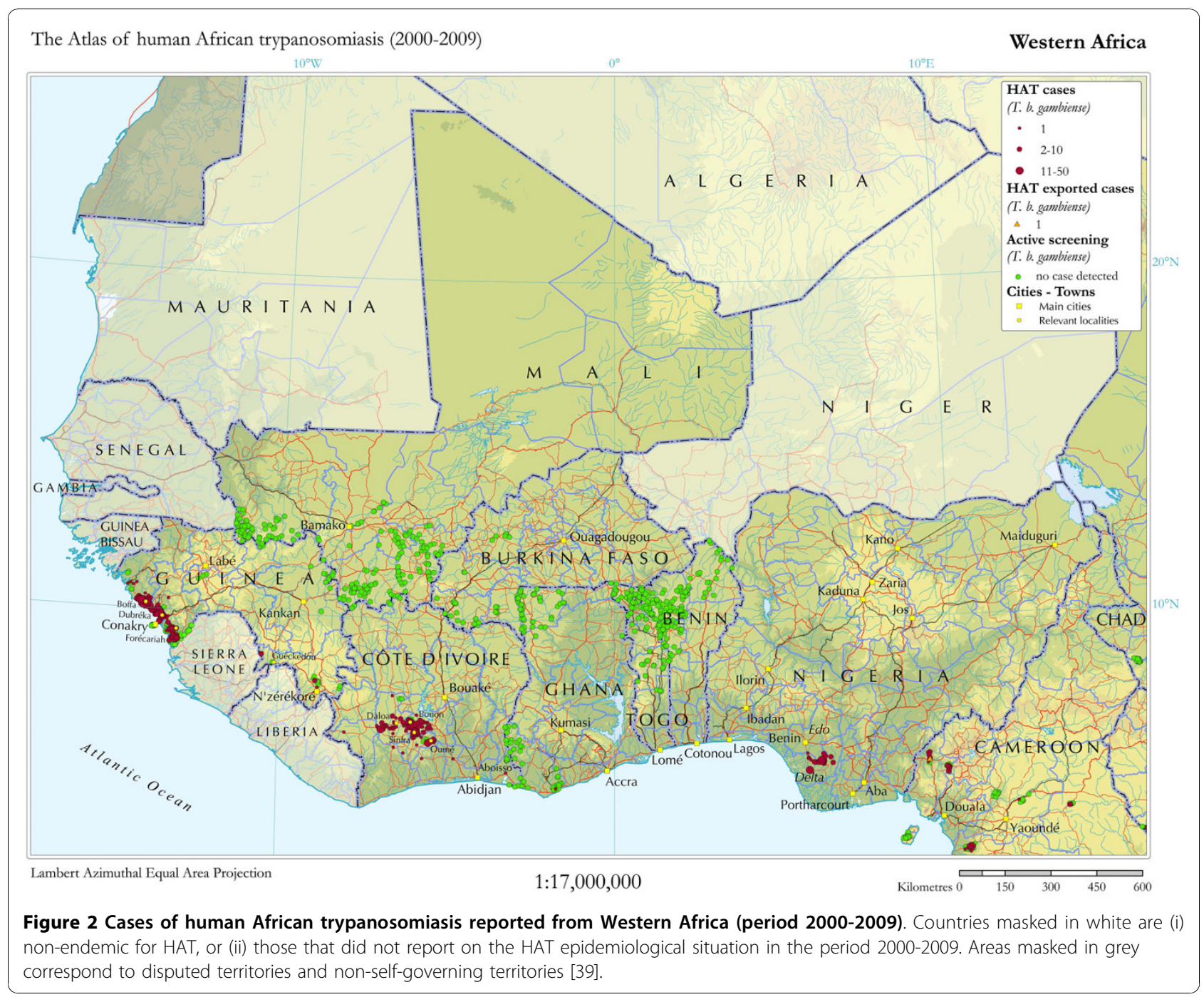

Region) and Oumé (Fromager Region). Sporadic cases are also reported from the South-eastern (Aboisso, Sud Comoe Region) and Western (Moyen Cavally Region) parts of the country.

Nigeria reports cases from Edo and Delta States, where security constraints prevent more accurate surveys that could delineate the exact extent of the focus. By contrast, extensive active screening surveys in Benin, Burkina Faso, Ghana, Mali and Togo have not revealed any evidence of transmission in vast areas of the Sudanian savannah ecoregion, which includes a number of sleeping sickness foci that had been active in the first part of the $20^{\text {th }}$ century [29]. This evolution appears to have been driven by demographic, climatic and landscape dynamics that would have shrunk the distribution of the tsetse fly in the region and reduced the possibility of contact between people and the vector of HAT [38]. The few cases detected in Burkina Faso in the last decade are due to returnees who had been working in HAT-endemic areas in Côte d'Ivoire [29].

\section{Central Africa}

The most active HAT foci of the Central African countries presented in this paper - which does not include Angola and DRC - are found in Sudan, Central African Republic, Congo and Uganda (Figure 3), most notably in riverine, forested biotopes where at-risk activities include attending to domestic chores, farming, fishing and hunting. A notable feature of HAT distribution in this region is the relevance of trans-boundary foci, associated to important population movements. These movements are often caused by insecurity, but also by the fact that borders frequently cut across areas inhabited by the same ethnic group.

In North-western Uganda most cases of Gambiense sleeping sickness are reported, listing from East to West, from the districts of Amuru, Adjumani, Moyo, Yumbe, 


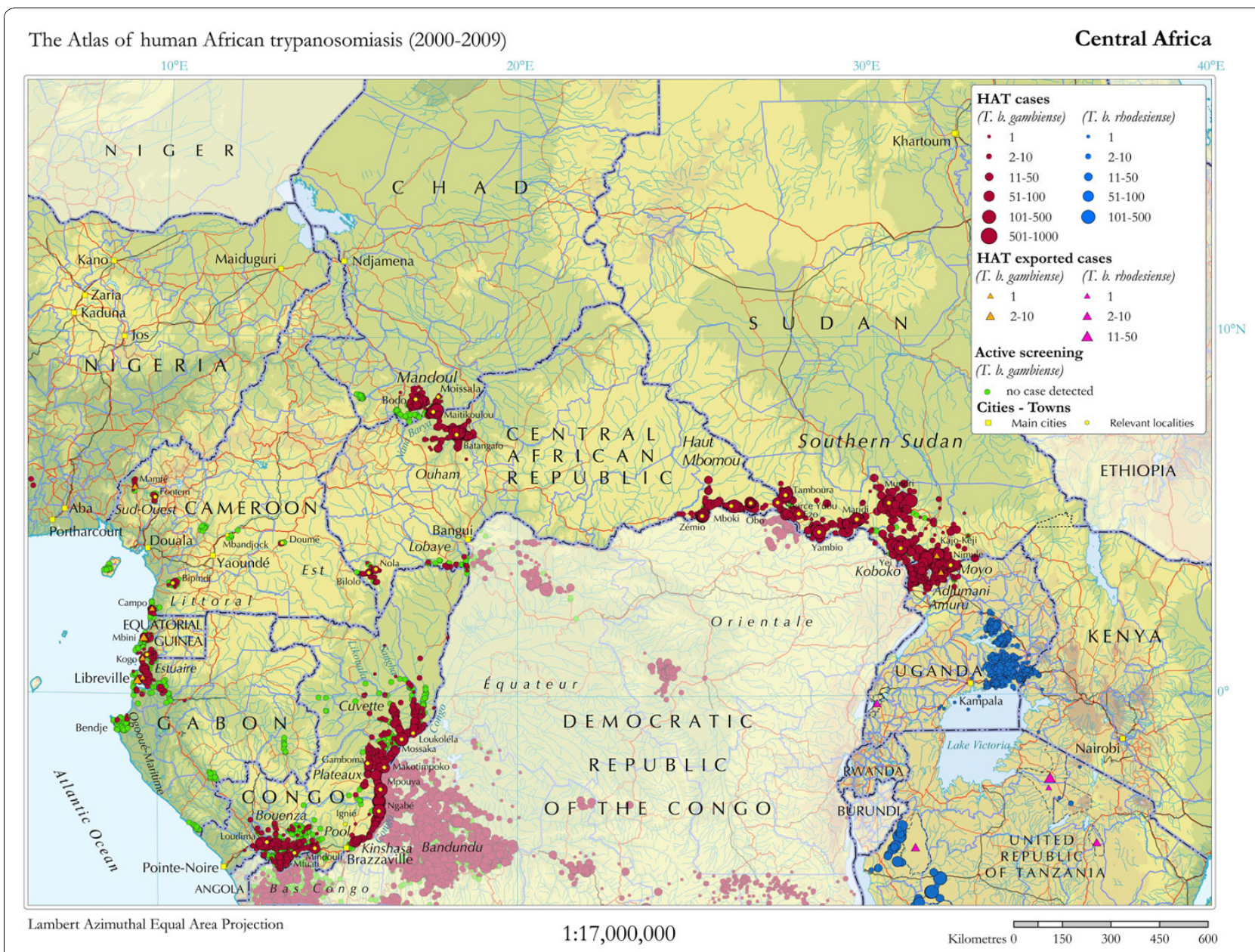

Figure 3 Cases of human African trypanosomiasis reported from Central Africa (period 2000-2009). Countries masked in white are (i) those where mapping is in progress, (ii) those that did not report on the HAT epidemiological situation in the period 2000-2009.

Arua, Maracha-Terego and Koboko, the latter providing most of the cases reported in recent years. In Southern Sudan, the main foci are, from East to West: Nimule and Kajo-Keji (linked to the Ugandan foci of Adjumani and Moyo), Yei, Mundri, Maridi, Yambio-Ezo (linked to the foci of the Oriental Province in DRC) and TamburaSource Yubu, related to the foci of Obo, Mboki and Zemio in the South East of Central African Republic (Haut-Mbomou Prefecture). The latter cluster of foci also extends southwards merging with the foci of Haut Uele in the Oriental Province of DRC. Central African Republic also includes the foci of Batangafo and Maitikoulou in the North West (Ouham Prefecture). Lower incidence is reported from the foci of Nola-Bilolo and Lobaye in the South, which is linked with the foci in Équateur Province of DRC. In Chad, HAT cases are reported only from the southern foci of Bodo and Moissala, associated to Mandoul and Nana Barya rivers and linked with the Central African foci of Batangafo and Maitikoulou. In Congo, HAT cases are concentrated in the Bouenza Region (foci of Loudima, Boko-Songho, Nkayi, Nkayes, Madingou, Mfouati and Yamba) and along the Congo River and its main tributaries (e.g. the Likouala and Sangha rivers), where the main foci are Loukolela and Mossaka (Cuvette Region), Gamboma, Mpouya and Makotimpoko (Plateaux Region) and Mindouli, Ignié and Ngabé (Pool Region). The transmission areas along the Congo River are also linked to the foci of Équateur, Bandundu, Kinshasa and Bas Congo Provinces in the DRC. Other less active foci in the forest biotope can be found in Cameroon (i.e. Mamfé and Fontem in the Sud-Ouest Province, Bipindi in the Littoral Province and Doumé in the Est Province).

The second important biotope of HAT transmission in Central Africa is the mangrove swamp along the Atlantic coast, where people are at risk of infection when engaged in fishing or hunting activities. In Cameroon we find the focus of Campo, also shared with Equatorial Guinea, which is followed southwards by the foci of Mbini and Kogo. The latter is linked to the focus of 


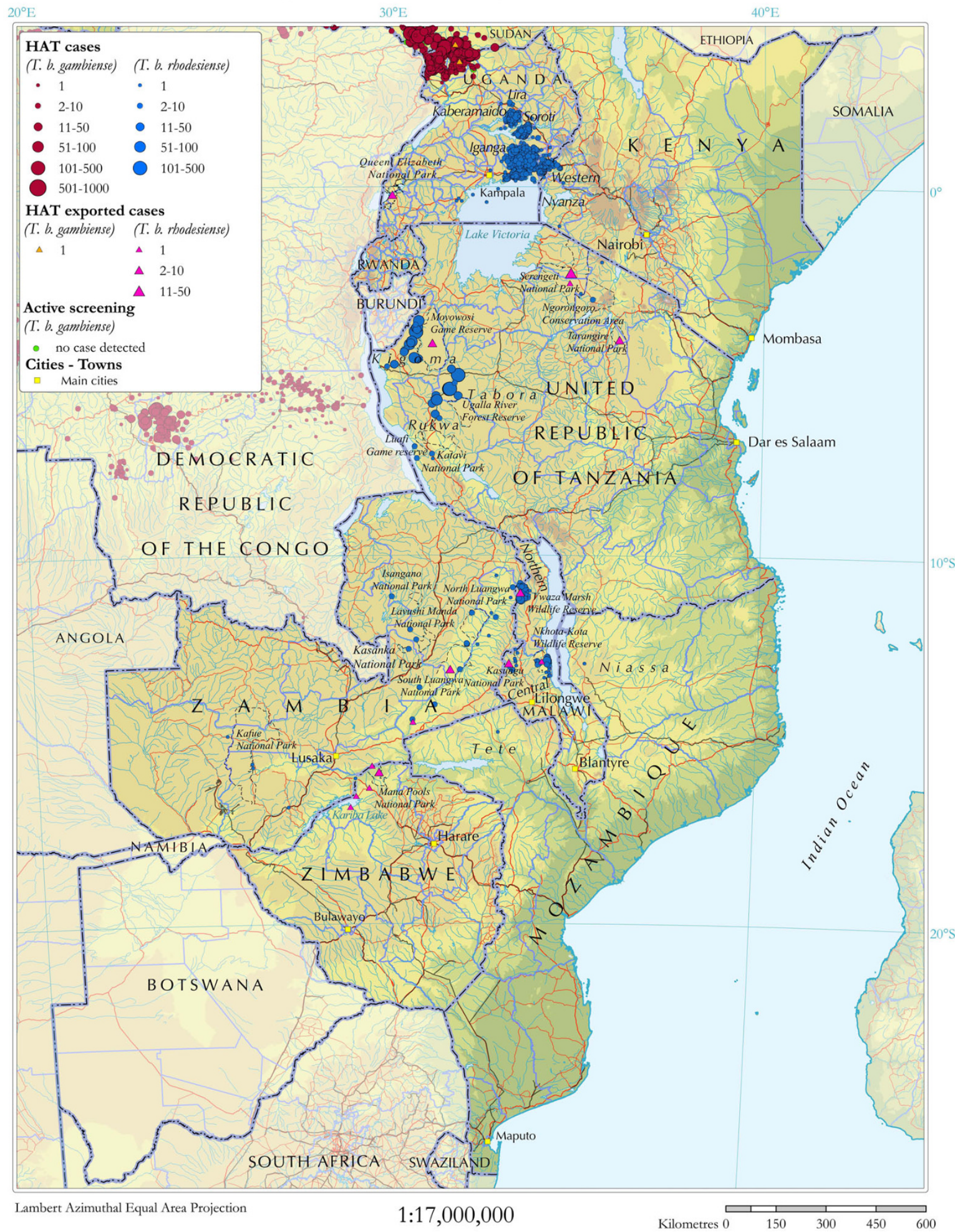

Figure 4 Cases of human African trypanosomiasis reported from Eastern and South-eastern Africa (period 2000-2009). Countries masked in white are (i) those were mapping is in progress, (ii) non-endemic for HAT, and (iii) those that did not report on the HAT epidemiological situation in the period 2000-2009. 
Noya in Gabon (Estuaire Province), and lastly the focus of Bendje (Ogooué-Maritime Province).

\section{Eastern and South-eastern Africa}

In Eastern and South-eastern Africa, affected by Rhodesiense HAT, at-risk activities are those that bring people into areas where livestock or wildlife interact with the tsetse vector. Among these activities are grazing livestock, collection of firewood and honey, hunting, fishing and poaching. Evidently, in addition to park rangers, tourists are among the categories at-risk, and a number of infections are diagnosed outside transmission areas in tourists that had visited protected areas. Infected tourists are considered as "exported cases" and mapped with purple triangles in points that are representative of the areas where they contracted the infection (most often the centroids of the visited parks).

Most reported cases of Rhodesiense sleeping sickness are linked to the livestock reservoir. Domestic cattle can be highly mobile, and their movements along trade routes and through livestock markets pose a serious challenge to Rhodesiense HAT control. In some countries these movements have been directly linked to the emergence of new foci of HAT transmission [40]. In particular, it has been shown that animals for sale at markets tend to have a higher prevalence of infection than animals in the general population; control of this spread therefore depends on close collaboration with veterinary services [41].

The livestock reservoir is especially important for South-eastern Uganda, which accounts for over 50 percent of T. $b$. rhodesiense cases reported from Africa in the period 2000-2009. Cases are mainly reported from the districts of Iganga, Soroti and Kaberamaido. The latter, together with the Dokolo and Lira Districts, only started to report a sizable number of cases in 2004 after the northwards movements of cattle and the movements of populations due to civil unrest. This northwards shift represents a real risk of merger with the Gambiense form that affects the North West of the country, which would pose significant problems for disease control [42]. Sporadic cases of $T . b$. rhodesiense have also been reported from the South-western part of Uganda in travellers visiting the Queen Elizabeth Park.

Domestic animals also play an important epidemiological role in other countries, including Tanzania, which reports over 30 percent of the total number of $T$. $b$. rhodesiense cases, and Kenya. In the latter country, HAT cases are reported from the Western Province (districts of Bungoma, Teso and Busia), with a few Kenyan cases being detected by health facilities across the Ugandan border. Sporadic cases are also reported from the Nyanza Province (Migori district).

Wildlife, especially game animals, is the other central actor in the epidemiology of Rhodesiense sleeping sickness.
Figure 4 shows the close spatial relationship between HAT infections and protected areas in those countries where the livestock (cattle) reservoir does not dominate. In a larger-scale example (Figure 5) the distribution of sleeping sickness cases around the Nkhotakota Wildlife Reserve in Malawi is shown. We note that a few circles identifying HAT cases are also found within the park's boundary, as they refer to park's workers (e.g. rangers), normally residing inside the park.

Zambia has been reporting cases linked to National Parks in the eastern and northern part of the country (i.e. National Parks of North and South Luangwa, Isangano, Kasanka and Lavushi Manda). HAT cases linked to Kafue National Park in the South-west of the country have also been reported. Cases detected in northern Zimbabwe are related to Mana Pools National Park and Kariba Lake. In Malawi, cases are clustered around Vwaza Marsh Wildlife Reserve (Northern Region), Nkhotakota Wildlife Reserve and Kasungu National Park (Central Region). Mozambique is reporting sporadic cases in Tete and Niassa Provinces. Tanzania reports cases of infection from the Serengeti and Tarangire National Parks and Ngorongoro Conservation Area in the northern part of the country. In the West, cases are reported from health facilities in the Kigoma Region related to the Moyowosi Game Reserve. Cases are also reported from Tabora Region linked to the Ugalla River Game Reserve and Rukwa Region linked to Luafi Game Reserve and Katavi National Park.

Interestingly, only the waters of Lake Tanganyika seem to separate the cases of $T . b$. gambiense in DRC from those of T. $b$. rhodesiense in Tanzania, thus posing a risk of merger between the two forms of the disease.

\section{Mapping accuracy}

The production of large scale, focus-level maps such as the one in Figure 5 is made possible by the accuracy of the geo-referencing procedures adopted for the Atlas. Results of the spatial accuracy assessment are summarized in Table 4, which provides the number of villages by country and by category of accuracy.

If the 23 study countries are considered as a whole, the proportion of villages belonging to the 4 categories of accuracy is 59.2 percent for "very high", 16.5 percent for "high", 17.1 percent for "medium" and 7.1 percent for "low". The resulting average accuracy, based on the estimated average error of the 4 categories, is approximately $900 \mathrm{~m}$.

It must be noted that the global accuracy of the Atlas is also potentially affected by homonymies, which can cause a case of HAT to be associated to the wrong village for the only reason of this having the same name as the correct one. It is impossible to estimate how often this may have occurred; however, thorough verifications are carried out to limit this kind of error to a minimum. 


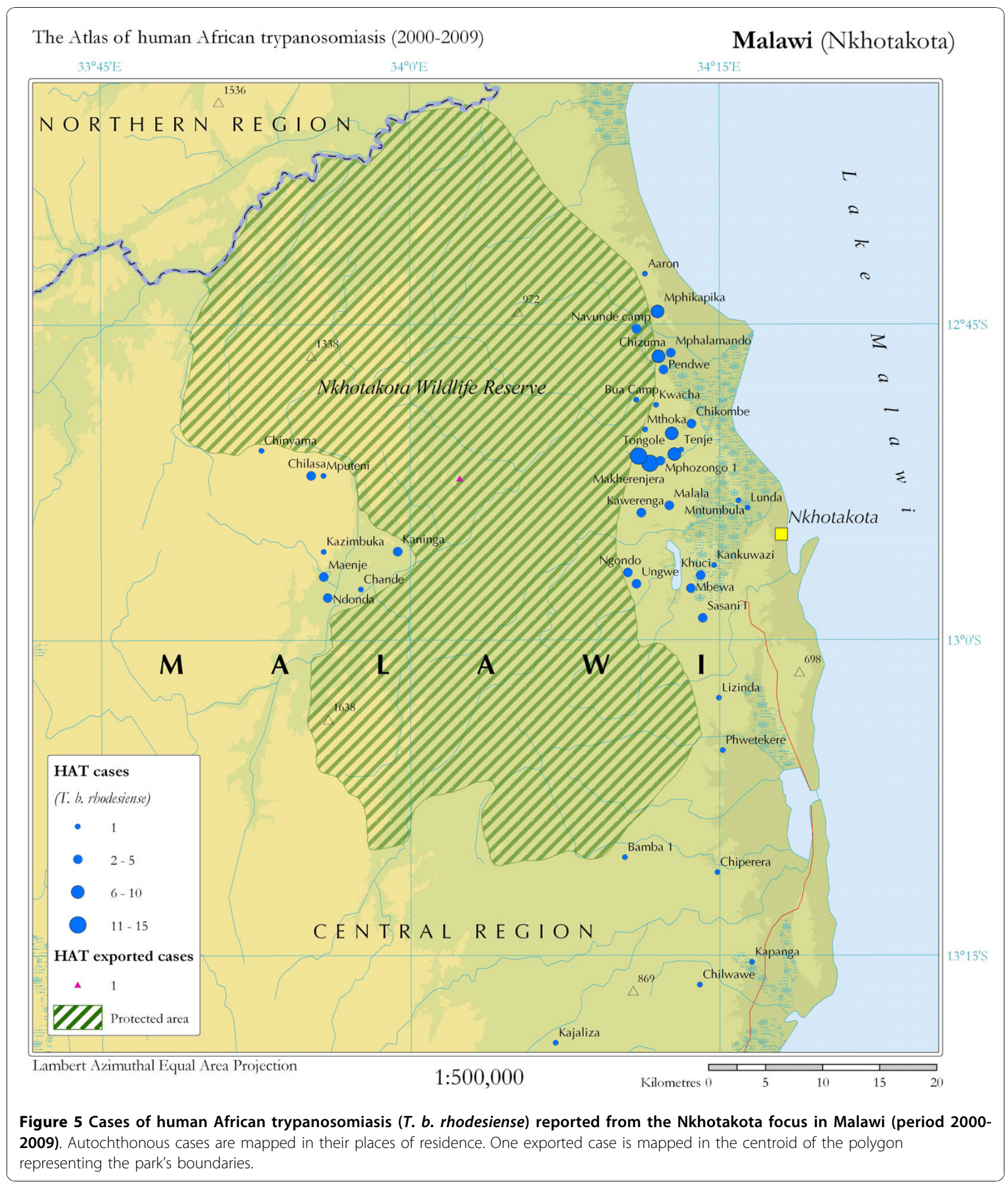

The Atlas of HAT as an epidemiological tool for planning, monitoring and evaluation of disease control

Maps of disease distribution are the first, more visible output of the HAT Atlas initiative. However, when the HAT geo-database is coupled with GIS software, it enables a range of epidemiological analyses to be performed, which are of great value for planning, monitoring and evaluating HAT control programmes. A few examples of the possible outputs of the Atlas for epidemiological analysis are given below. 
Table 4 Geographical accuracy of mapped villages

\begin{tabular}{|c|c|c|c|c|c|}
\hline \multirow[t]{2}{*}{ Country } & \multicolumn{4}{|c|}{$\begin{array}{l}\text { Category of accuracy for } \\
\text { mapped villages (number of } \\
\text { villages) }\end{array}$} & \multirow[t]{2}{*}{$\begin{array}{c}\text { Average } \\
\text { accuracy }(\mathrm{m})\end{array}$} \\
\hline & $\begin{array}{l}\text { Very } \\
\text { high }\end{array}$ & High & Moderate & Low & \\
\hline Benin & 99 & 71 & 21 & 3 & 600 \\
\hline Burkina Faso & 27 & 1 & 0 & 4 & 700 \\
\hline Cameroon & 76 & 19 & 16 & 0 & 500 \\
\hline $\begin{array}{l}\text { Central African } \\
\text { Republic }\end{array}$ & 251 & 65 & 32 & 49 & 900 \\
\hline Chad & 101 & 43 & 49 & 13 & 1,000 \\
\hline Congo & 476 & 253 & 65 & 80 & 800 \\
\hline Côte d'Ivoire & 145 & 60 & 19 & 5 & 500 \\
\hline Equatorial Guinea & 70 & 18 & 22 & 1 & 700 \\
\hline Gabon & 79 & 84 & 52 & 22 & 1,200 \\
\hline Ghana & 65 & 31 & 0 & 0 & 200 \\
\hline Guinea & 243 & 19 & 1 & 3 & 100 \\
\hline Kenya & 25 & 2 & 0 & 0 & 100 \\
\hline Malawi & 7 & 7 & 69 & 23 & 2,700 \\
\hline Mali & 107 & 99 & 1 & 0 & 300 \\
\hline Mozambique & 0 & 0 & 0 & 2 & 5,000 \\
\hline Nigeria & 14 & 2 & 3 & 4 & 1,300 \\
\hline Rwanda & 0 & 0 & 0 & 0 & - \\
\hline Sudan & 148 & 30 & 345 & 88 & 2,200 \\
\hline Togo & 79 & 9 & 2 & 0 & 100 \\
\hline Uganda & 1,216 & 86 & 233 & 85 & 700 \\
\hline $\begin{array}{l}\text { United Republic of } \\
\text { Tanzania }\end{array}$ & 32 & 1 & 2 & 5 & 800 \\
\hline Zambia & 5 & 10 & 10 & 4 & 1,700 \\
\hline Zimbabwe & 1 & 1 & 1 & 2 & 2,600 \\
\hline Total & 3,266 & 911 & 943 & 393 & 900 \\
\hline
\end{tabular}

Number of mapped villages falling within each of the four categories of geographical accuracy (by country) and average mapping accuracy (in metres).

Figure 6A allows to monitor whether mobile teams correctly plan active case finding surveys.

The map shows that a sizable number of cases are reported by passive surveillance from an area north of Bodo (Chad) where no active screening was undertaken in the last five years. This indicates that, when planning for the next surveys, mobile teams should broaden the geographical scope of their activities to include this area of transmission.

Figure 6B allows to evaluate the NSSCP capacity for early case detection, which has vast implications for treatment outcome, people's welfare and long-term disease control. The ratio $\left(S_{2}-S_{1}\right) /\left(S_{1}+S_{2}\right)$ is used, where $S_{1}$ and $S_{2}$ are the numbers of HAT cases in first and second stage respectively. We note that, predictably, cases reported from non-surveyed villages tend to display high rates of second stage infections $\left(\left(S_{2}-S_{1}\right) /\left(S_{1}+\right.\right.$ $\left.\mathrm{S}_{2}\right)>0.50$ ). It must be noted that there are gaps in the field 'disease stage' of the HAT DB, as stage is not always recorded and included in the reports. This explains why for a few of the lilac circles in (A) there are no corresponding circles in (B). In this respect, more recent data (i.e. 2005-2009) are comparatively more complete than older data (i.e. 2000-2004), due to improved recording and reporting.

Another example of the Atlas as a tool for monitoring and evaluation of control activities is in Figure 7, which shows a time series of maps for the focus of Mbini (Equatorial Guinea).

Despite active case-finding surveys and subsequent treatment of detected cases, the focus of Mbini presents a fairly stable epidemiological pattern and the number of new infections does not show signs of abatement. The strategy for HAT control in the area should therefore be reinvigorated. Thanks to the HAT DB, another factor could be added to this analysis by estimating the ratio of 'number of people screened' to 'census', which would clarify whether poor performance in reducing the number of new HAT cases can be ascribed to insufficient coverage of active screenings, and therefore if sensitization activities should be contemplated.

\section{Discussion}

The dramatic development of geospatial technologies has revolutionized disease mapping by providing tools of unprecedented accuracy, coverage and affordability [43-45]. However, several other factors, many of which are disease-specific, impinge on the mapping of neglected tropical diseases. Epidemiology, ecology, diagnosis, treatment, as well as political and financial commitment, all contribute to shaping how global disease maps are or can be generated. If treatment is looked at, we notice that the existence of safe and affordable drugs against schistosomiasis and soil-transmitted helminthiases enables mass drug administration schemes to be implemented, thus making detection and mapping of individual cases unnecessary in many instances [46]; this fact, combined with the high prevalence of these infections, has led to mapping approaches based on reviews of community-based surveys, whose results can be extrapolated or interpolated to provide regional or global coverage [47-49]. Disease ecology is also central to mapping, in that it can help define bioclimatic and biogeographic envelopes within which a pathogen or its vector can occur. This is aptly demonstrated by rapid epidemiological mapping methods, first developed for targeting interventions against onchocerciasis [50,51], and now also proposed for soil-transmitted helminthiases [46], schistosomiasis [52], and loiasis [53]. Diagnostic methods, and their sensitivity, specificity and cost, can also have a major impact on disease mapping, as proved by the repercussions that a new diagnostic tool [54] had on global mapping of lymphatic filariasis 


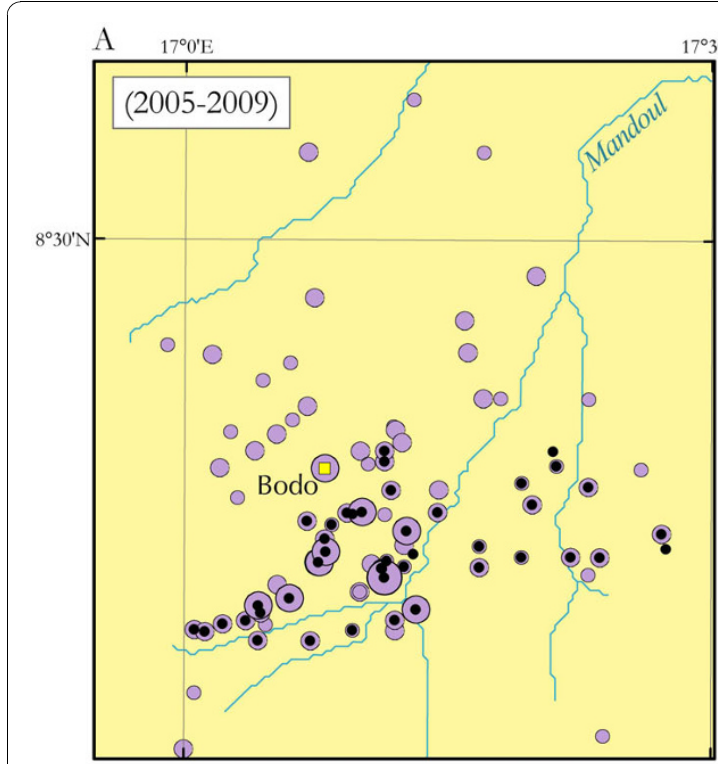

$1: 1,000,000$

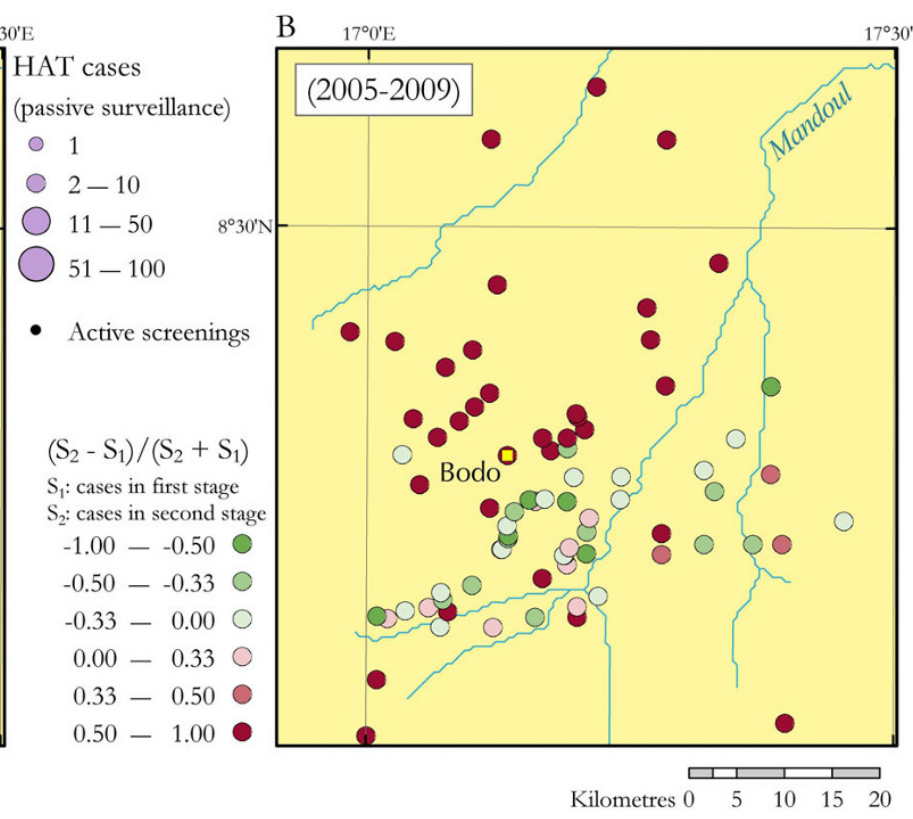

Figure 6 HAT focus of Bodo in Chad (period 2005-2009). A: Villages where HAT cases were detected through passive surveillance (lilac circles) and villages where active case-finding activities were carried out (black dots). B: Disease stage ratio ( $\mathrm{S}_{1}$ : first stage, $\mathrm{S}_{2}$ : second stage)

$[55,56]$ From an institutional standpoint, coordination at the international level is fundamental to develop protocols for systematic and comparable mapping, as demonstrated by such initiatives as the global Dracunculiasis Eradication Program [57], the Global Programme to eliminate lymphatic filariasis [58], the Onchocerciasis
Control Programme in West Africa and the African Programme for Onchocerciasis Control [51].

All these factors also shape sleeping sickness mapping. The severity of HAT outcomes and the toxicity of available drugs require case-by-case diagnosis [59]. A complex interplay of ecological factors, not yet fully understood,

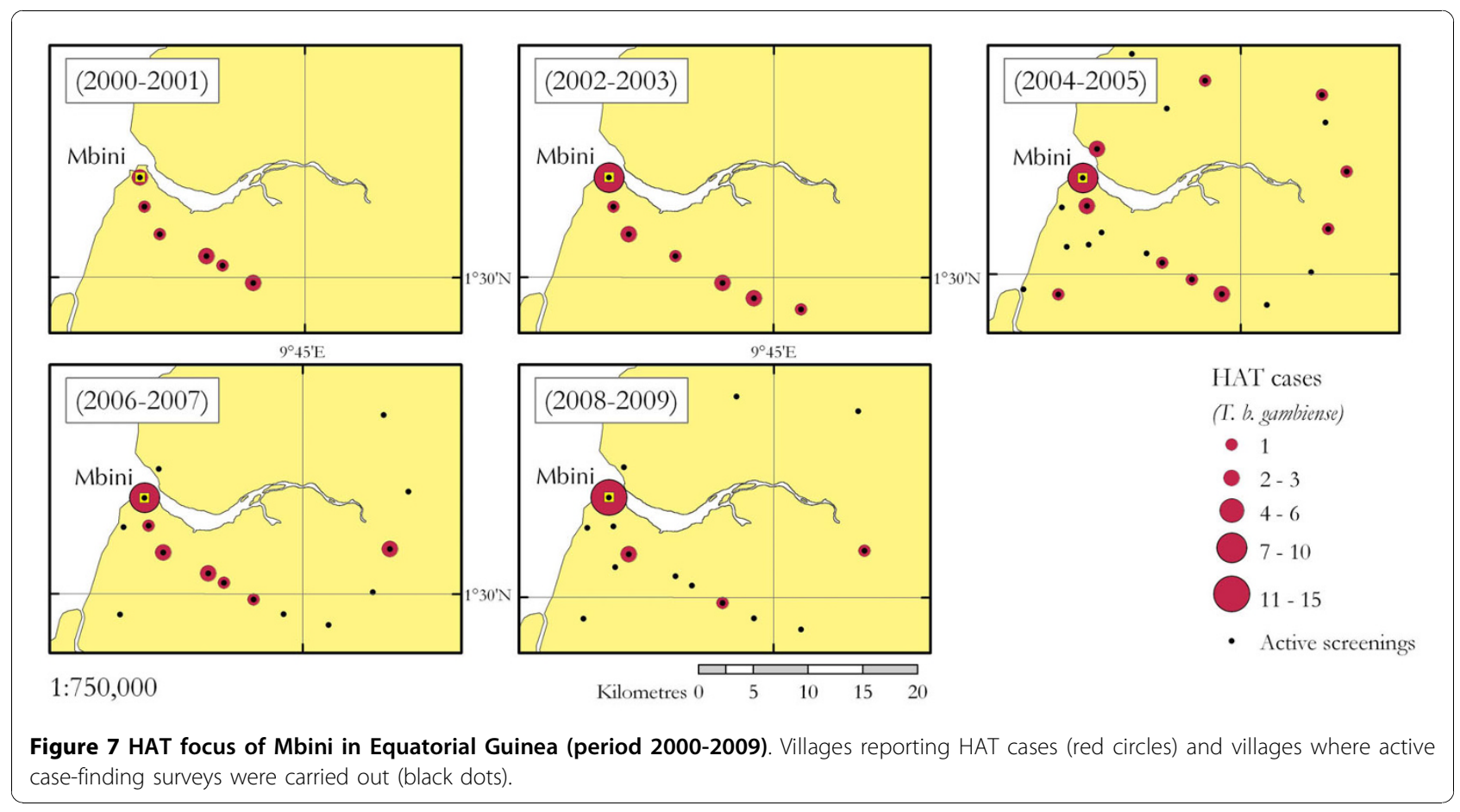


determines the pronounced focal nature of HAT [22]. Notwithstanding variations in transmission intensity, the geographic distribution of sleeping sickness foci in Africa has proved fairly stable over time, especially for the Gambiense form, thus helping to target costly mass-screening activities to the known areas of endemicity. On the other hand, at a more local level, HAT also exhibits complex spatial and temporal dynamics, with abatements and resurgences [60,61], contractions, local eliminations [62], shifts and spreads [63], which call for a detailed representation in space and time. Another feature of sleeping sickness epidemiology that has relevance for mapping is the occurrence of disease-free villages lying alongside endemic ones. Heterogeneities at this fine scale make village-level mapping a necessity, both for disease control and management [10] and also in those contexts where the goal is local disease elimination [62]. The level of detail of this Atlas exceeds that of MDA programmes and is comparable with the level reached by the eradication programmes.

The importance of an adequate framework for coordination and collaboration among stakeholders can not be overstated. Several resolutions of the World Health Assembly calling to reinforce links with FAO and increase awareness in the international community $[20,21]$ spurred WHO to bring together national health authorities in the affected countries and international partners (FAO/PAAT, NGOs, Research Institutes), thus making HAT global mapping possible. One of the many fields in which coordination contributes to global mapping is the WHO-promoted harmonization of survey and annual reports, which streamlined the flow of information and simplified data analysis.

When utilizing the outputs of the HAT Atlas initiative it is essential to consider that sleeping sickness is a disease of complex diagnosis and management, which occurs in remote rural areas where health facilities are weak or even absent. The risk of under-detection and underreporting is ever-present, due to possible lapses of the health information systems and difficulties in accessing some transmission areas because of remoteness or insecurity [64]. HAT can also be misdiagnosed with more common diseases presenting similar clinical signs and symptoms. The combined effect of these factors can confound the real status of the disease, and the risk of this happening was extremely high during the 1990s. However, this risk has since been reduced as a result of two major developments: (i) discontinuation of social upheavals and civil strife in most affected countries, which facilitated access to endemic areas; and (ii) intensified efforts by NGOs, bilateral cooperation and in particular by WHO that, thanks to a successful PublicPrivate Partnership, increased its support to affected countries, thus leading to strengthened HAT control and reporting. Keeping these efforts up will be crucial to sustain and scale up the achieved results.

Despite substantial progress in the accuracy and completeness of HAT reporting and mapping, a relatively small proportion of HAT reported cases (fewer that $10 \%)$ still can not be located at the village-level. Unravelling of these situations relies on progressive acquisition of more detailed information. The burdensome process of progressively filling the various gaps will continue, ultimately aiming at mapping all reported cases at the village level. Searches for data will only be discontinued if and where insurmountable hurdles to further improvement should arise. Importantly, all of the unmapped cases originate from known foci, so that their absence from the maps has a limited impact on the delineation of HAT transmission areas.

From the methodological standpoint, it must be stressed that no specific structure or large-scale data collection activity specifically aimed at global mapping was put in place for the Atlas of HAT. The Atlas ultimately relies on the reinforced network of NSSCPs, NGOs, Research Institutions and on the optimal use of HAT data available at WHO, coupled with the appropriate use of public-domain geographical databases.

\section{Conclusions}

The maps presented in this paper represent the state of knowledge of HAT geographic distribution in 23 out of 25 HAT-endemic countries that reported on sleeping sickness occurrence during the past ten years (period 2000-2009). These maps are the result of the coordinating and leadership role of WHO, the partnership with $\mathrm{FAO} / \mathrm{PAAT}$, and of the thorough analysis of unpublished epidemiological reports provided by all stakeholders involved in HAT control. These maps constitute a remarkable improvement on previous information available on this topic (e.g. [22]). The average mapping error (approximately $900 \mathrm{~m}$ ), and the overall completeness (i.e. 90.3 percent of all reported cases were mapped) make the outputs suitable for a range of technical and scientific applications.

The Atlas of HAT provides more than maps. Ministries of Health, NGOs and Research Institutions can use the Atlas, and the HAT data repository that underpins it, to monitor the impact of control activities, assess epidemiological trends and plan control or research activities. Also, it will be possible to combine HAT maps with the increasing amount of geospatial datasets, including human and livestock population layers, tsetse distribution map, land cover datasets, etc. [65], with a view to improving risk assessment and generating evidence-based estimates of population at risk and disease burden. The HAT data repository will also help NSSCPs 
prevent data losses, which have been a frequent occurrence in the history of sleeping sickness, mainly due to the challenging circumstances in which HAT control is carried out.

Although initially designated to cover the period 2000 - 2009, the Atlas is a dynamic tool that will be regularly updated as new information becomes available. The present focus is on the completion of the continental map, by completing mapping in Angola and DRC. At the same time, the whole database will be refined by progressively including more precise geographic coordinates and attempting to map the remaining missing villages. Finally, HAT-silent countries (i.e. Burundi, Ethiopia, Gambia, Guinea-Bissau, Liberia, Niger, Senegal and Sierra Leone) will undertake HAT assessments to clarify their epidemiological status.

In order to maximize the impact and ensure sustainability of the HAT Atlas initiative, capacity at the country level will be strengthened through training and provision of equipment, so that optimal usage of the Atlas can be made by NSSCPs, and future yearly updating can be envisaged at the country-level. Capacity building will also aim at reinforcing the sense of ownership of this tool in HAT-affected countries. A range of dissemination media and outreach activities are anticipated, including an Atlas proper that will provide disease maps at different scales, as well as indexed and georeferenced endemic locations. At the end of the process, the Atlas will be made available in the public domain free-of-charge through WHO and FAO/PAAT websites.

\section{Disclaimers}

The boundaries and names shown and the designations used on the maps presented in this paper do not imply the expression of any opinion whatsoever on the part of WHO and FAO concerning the legal status of any country, territory, city or area or of its authorities, or concerning the delimitation of its frontiers or boundaries. Dotted lines on maps represent approximate border lines for which there may not yet be full agreement.

The views expressed in this paper are those of the authors and do not necessarily reflect the views of WHO and FAO.

\footnotetext{
Acknowledgements

The activities described in this paper are an initiative of the Department of Control of Neglected Tropical Diseases - World Health Organization. They were implemented through a technical collaboration between WHO and FAO in the framework of the PAAT.

The authors would like to acknowledge all institutions that provided the epidemiological data used as input to this study: the National Sleeping Sickness control Programmes and national health authorities of Benin, Burkina Faso, Cameroon, Central African Republic, Chad, Congo, Côte d'Ivoire, Equatorial Guinea, Gabon, Ghana, Guinea, Kenya, Malawi, Mali, Mozambique, Nigeria, Rwanda, Sierra Leone, Sudan, Togo, Uganda, United
}

Republic of Tanzania, Zambia and Zimbabwe; the NGOs "Médecins sans frontières", Epicentre, Malteser and Merlin; and the Research Institutions "Institut de Recherche pour le Développement", "Institut Pierre Richet" (Côte d'Ivoire), "Projets de Recherches Cliniques contre la Trypanosomiase" (Côte d'Ivoire), "Centre International de Recherche-Développement sur l'Élevage en zone Sub-humide" (Burkina Faso), The Centre for Infectious Disease, College of Medicine and Veterinary Medicine, The University of Edinburgh. This work also benefited from the HAT mapping activities carried out by Dr. P. Bureau and Mr. P. Lucas in Central Africa in the 1990s.

The work of GC was supported by two FAO projects: "Strengthening the Information System of PAAT" (GCP/RAF/403/IFA), and "Pro-poor Integrated Packages to Enhance Policy and Decision Making against the African Animal Disease Burden in sub-Saharan Africa" (GCP/RAF/442/IFA), both funded by the International Fund for Agricultural Development (IFAD). GC was also supported by WHO. Funds for MP's activities were provided by $\mathrm{WHO}$ and FAO. EMF was supported by the Wellcome Trust (085308) and WHO. FC was supported by the French "Ministère des Affaires Etrangères et Européennes" (project "Fonds de Santé Prioritaire - Recherche en Entomologie Formation et Stratégie").

\section{Author details}

${ }^{1}$ World Health Organization, Control of Neglected Tropical Diseases, Innovative and Intensified Disease Management, 1211 Geneva 27, Switzerland. ${ }^{2}$ Food and Agriculture Organization of the United Nations, Animal Production and Health Division, Viale delle Terme di Caracalla, 00153, Rome, Italy. ${ }^{3}$ World Health Organization, Regional Office for Africa, Brazzaville, Congo. ${ }^{4}$ World Health Organization, Regional Office for the Eastern Mediterranean, Cairo 11371, Egypt. ${ }^{5}$ Centre for Infectious Diseases, University of Edinburgh, Ashworth Laboratories, Kings Buildings, West Mains Road, Edinburgh EH9 3JT, UK. 'Institut de Recherche pour le Développement UMR 177, Centre International de Recherche Développement sur l'Elevage en zone Subhumide, Bobo-Dioulasso, Burkina Faso.

\section{Authors' contributions}

PPS coordinated the HAT Atlas initiative. GC supervised the technical aspects related to data management and GIS. PPS and GC jointly drafted the manuscript. PPS, JRF, AD, JAR and JGJ collated and screened epidemiological data used as input. GC, MP, EMF and PPS designed and developed the logical and physical structure of the database of HAT. MP, GC and FC implemented geo-positioning procedures and entered data. EMF and FC provided perspectives on HAT epidemiology. PPS, RCM and JGJ coordinated and supervised the collaboration between $\mathrm{WHO}$ and FAO in the framework of PAAT. All authors have contributed to conceptualizing the manuscript, and commented on and approved the final draft.

\section{Competing interests}

The authors declare that they have no competing interests.

Received: 1 September 2010 Accepted: 1 November 2010

Published: 1 November 2010

\section{References}

1. Remme J, Feenstra P, Lever P, Médici A, Morel C, Noma M, Ramaiah K, Richards F, Seketeli A, Schmunis G: Tropical diseases targeted for elimination: Chagas disease, lymphatic filariasis, onchocerciasis, and leprosy. A custom publication of the Disease Control Priorities Project 2006, 147 [http://files.dcp2.org/pdf/DCP/DCP22.pdf].

2. Setel PW, Macfarlane SB, Szreter S, Mikkelsen L, Jha P, Stout S, AbouZahr C: A scandal of invisibility: making everyone count by counting everyone. The Lancet 2007, 370:1569-1577.

3. World Health Organization: Global plan to combat neglected tropical diseases 2008-2015. Geneva; 2007 [http://whqlibdoc.who.int/hq/2007/ WHO_CDS_NTD_2007.3_eng.pdf].

4. Hotez PJ, Molyneux DH, Fenwick A, Ottesen E, Ehrlich Sachs S, Sachs JD: Incorporating a Rapid-Impact Package for Neglected Tropical Diseases with Programs for HIV/AIDS, Tuberculosis, and Malaria. PLOS Med 2006, 3: e102.

5. Lammie PJ, Fenwick A, Utzinger J: A blueprint for success: integration of neglected tropical disease control programmes. Trends Parasitol 2006, 22:313-321. 
6. World Health Organization: Operational Guidelines for Rapid Mapping of Bancroftian Filariasis in Africa. Geneva; 2000 [http://whqlibdoc.who.int/hq/ 2000/WHO_CDS_CPE_CEE_2000.9.pdf].

7. Macè $J M$, Boussinesq $M$, Ngoumou P, Enyegue Oye J, Koeranga A, Godin C: Country-wide rapid epidemiological mapping of onchocerciasis (REMO) in Cameroon. Ann Trop Med Parasitol 1997, 91:379-391 [http://horizon. documentation.ird.fr/exl-doc/pleins_textes/pleins_textes_6/b_fdi_47-48/ 010010919.pdf].

8. World Health Organization: Report of the 2nd Global Scientific Meeting on Trachoma. Geneva; 2003 [http://www.who.int/blindness/2nd\% 20GLOBAL\%20SCIENTIFIC\%20MEETING.pdf].

9. World Health Organization: Global programme to eliminate lymphatic filariasis. Weekly Epidemiological Record 2008, 83:333-348 [http://www.who. int/wer/2008/wer8337_38.pdf].

10. Cattand P, Jannin J, Lucas P: Sleeping sickness surveillance: an essential step towards elimination. Trop Med Int Health 2001, 6:348-361.

11. World Health Organization: Report of the Fifth Consultative Meeting on Leishmania/HIV Coinfection. Addis Ababa, Ethiopia; 2007 [http://www.who. int/leishmaniasis/resources/Leishmaniasis_hiv_coinfection5.pdf].

12. Moncayo A: Chagas disease: current epidemiological trends after the interruption of vectorial and transfusional transmission in the Southern Cone countries. Mem Inst Oswaldo Cruz 2003, 98:577-591.

13. World Health Organization: Dracunculiasis eradication - global surveillance summary, 2009. Weekly epidemiological record 2010, 85:166-176[http://www.who.int/entity/wer/2006/wer8108.pdf].

14. Anand S, Hanson K: Disability-adjusted life years: a critical review. J Health Econ 1997, 16:685-702[http://info.worldbank.org/etools/docs/library/48283/ 20506.pdf].

15. Williams A: Calculating the global burden of disease: time for a strategic reappraisal? Health Econ 1999, 8:1-8[http://info.worldbank.org/etools/docs/ library/48282/20505.pdf].

16. Engels D, Savioli L: Reconsidering the underestimated burden caused by neglected tropical diseases. Trends Parasitol 2006, 22:363-366.

17. Mathers CD, Ezzati M, Lopez AD: Measuring the burden of neglected tropical diseases: the global burden of disease framework. PLOS Negl Trop Dis 2007, 1:e114.

18. Bern C, Maguire JH, Alvar J: Complexities of assessing the disease burden attributable to leishmaniasis. PLoS Negl Trop Dis 2008, 2:e313.

19. Fèvre EM, Wissmann BV, Welburn SC, Lutumba P: The burden of human african trypanosomiasis. PLOS Negl Trop Dis 2008, 2:e333.

20. World Health Organization: Resolution $50.36,50^{\text {th }}$ World Health Assembly. Geneva; 1997.

21. World Health Organization: Resolution $56.7,56^{\text {th }}$ World Health Assembly. Geneva; 2003 [http://apps.who.int/gb/archive/pdf_files/WHA56/ea56r7.pdf].

22. World Health Organization: Control and surveillance of African trypanosomiasis. Geneva; 1998 [http://whqlibdoc.who.int/trs/ WHO_TRS_881.pdf].

23. Christy C: The Distribution of Sleeping Sickness, Filaria perstans, etc., in East Equatorial Africa. Rep Sleep Sickn Comm Roy Soc 1903, 2:2-8.

24. Gouzien P: La maladie du sommeil dans le Haut-Sénégal et Niger. Ann Hyg Med Coloniales 1908, 11:29-71.

25. Pittaluga G: Informe de la Comisión del Instituto Nacional de Higiene de Alfonso XIII enviada a las posesiones españolas del golfo de Guinea para el estudio de la enfermedad del sueño. [Report of the Mission of the Instituto Nacional de Higiene Alfonso XIII sent to Spanish territories in the Gulf of Guinea to study Sleeping Sickness]. Madrid: Imprenta artística J. Blass y Cia; 1910

26. Cecchi G, Paone M, Franco J, Fevre E, Diarra A, Ruiz J, Mattioli R, Simarro P. Towards the Atlas of human African trypanosomiasis. Int $J$ Health Geogr 2009, 8:15 [http://www.ij-healthgeographics.com/content/8/1/15].

27. World Health Organization: Human African trypanosomiasis (sleeping sickness): epidemiological update. Weekly epidemiological record 2006, 81:71-80 [http://www.who.int/entity/wer/2006/wer8108.pdf].

28. Simarro PP, Jannin J, Cattand P: Eliminating Human African Trypanosomiasis: Where Do We Stand and What Comes Next. PLoS Med 2008, 5:e55.

29. Cecchi G, Courtin F, Paone M, Diarra A, Franco JR, Mattioli RC, Simarro PP: Mapping sleeping sickness in Western Africa in a context of demographic transition and climate change. Parasite 2009, 16:99-106 [ftp://ftp.fao.org/docrep/fao/article/ak244e.pdf].
30. Dooley J: An inventory and comparison of globally consistent geospatial databases and libraries. Rome: Food and Agriculture Organization of the United Nations; 2005 [http://www.fao.org/docrep/008/a0118e/a0118e00. htm].

31. Allsopp R, Phillemon-Motsu T: Tsetse control in Botswana-a reversal in strategy. Pestic Outlook 2002, 13:73-76 [http://www.rsc.org/ej/PO/2002/ b202993f.pdf].

32. Kgori PM, Modo S, Torr SJ: The use of aerial spraying to eliminate tsetse from the Okavango Delta of Botswana. Acta Trop 2006, 99:184-199.

33. Kgori PM, Modo S: Transboundary programme to eliminate tsetse from the River frontiers of Botswana and Namibia using the sequential aerial spraying technique. 30th Meeting of the International Scientific Council for Trypanosomiasis Research and Control (ISCTRC); Kampala, Uganda 2009.

34. Goddard J: Infectious diseases and arthropods. Totowa: Humana Press; 2000.

35. Leak SGA: Tsetse biology and ecology: their role in the epidemiology and control of trypanosomosis. Wallingford: CAB International (in association with the International Livestock Research Institute, Nairobi, Kenya); 1998.

36. Saini RK, Simarro PP: Tsetse survey in Swaziland - Report to the World Health Organization. 2008 [http://www.who.int/trypanosomiasis_african/ resources/The_HAT_atlas.pdf].

37. World Health Organization: Prospection médicale de la trypanosomiase humaine africaine dans le district de Kambia dans le nord-ouest de la Sierra Leone à la frontière de la Guinée - Unpublished report. Geneva; 2010.

38. Courtin F, Jamonneau V, Duvallet G, Garcia A, Coulibaly B, Doumenge JP, Cuny G, Solano P: Sleeping sickness in West Africa (1906-2006): changes in spatial repartition and lessons from the past. Trop Med Int Health 2008, 13:334-344.

39. Food and Agriculture Organization of the United Nations: Global Administrative Unit Layers (GAUL): Technical Aspects. Rome; 2008 [http:// www.foodsec.org/tools_gaul.htm].

40. Fèvre EM, Coleman PG, Odiit M, Magona JW, Welburn SC, Woolhouse ME: The origins of a new Trypanosoma brucei rhodesiense sleeping sickness outbreak in eastern Uganda. Lancet 2001, 358:625-628.

41. Fèvre EM, Tilley A, Picozzi K, Fyfe J, Anderson I, Magona JW, Shaw DJ, Eisler MC, Welburn SC: Central point sampling from cattle in livestock markets in areas of human sleeping sickness. Acta Trop 2006, 97:229-232.

42. Picozzi K, Fevre EM, Odiit M, Carrington M, Eisler MC, Maudlin I, Welburn SC: Sleeping sickness in Uganda: a thin line between two fatal diseases. BMJ 2005, 331:1238-1241.

43. Kitron U: Landscape ecology and epidemiology of vector-borne diseases: tools for spatial analysis. J Med Entomol 1998, 35:435-445.

44. Bergquist $\mathrm{N}$ : Vector-borne parasitic diseases: new trends in data collection and risk assessment. Acta Trop 2001, 79:13-20.

45. Rogers $D$, Randolph S: Studying the global distribution of infectious diseases using GIS and RS. Nat Rev Microbiol 2003, 1:231-236.

46. World Health Organization: Preventive chemotherapy in human helminthiasis. Coordinated use of anthelminthic drugs in control interventions: guidelines for health professionals and programme managers. Geneva; 2006 [http://whqlibdoc.who.int/publications/2006/ 9241547103_eng.pdf].

47. Brooker S, Rowlands M, Haller L, Savioli L, Bundy DA: Towards an atlas of human helminth infection in sub-Saharan Africa: the use of geographical information systems (GIS). Parasitol Today 2000, 16:303-307.

48. Engels D, Chitsulo L, Montresor A, Savioli L: The global epidemiological situation of schistosomiasis and new approaches to control and research. Acta Trop 2002, 82:139-146.

49. Brooker S, Kabatereine N, Smith J, Mupfasoni D, Mwanje M, Ndayishimiye O, Lwambo N, Mbotha D, Karanja P, Mwandawiro C, et al: An updated atlas of human helminth infections: the example of East Africa. Int $J$ Health Geogr 2009, 8:42 [http://www.ij-healthgeographics.com/content/8/1/42].

50. Ngoumou P, Walsh JF, Mace JM: A rapid mapping technique for the prevalence and distribution of onchocerciasis: a Cameroon case study. Ann Trop Med Parasitol 1994, 88:463-474.

51. Basáñez M, Pion S, Churcher T, Breitling L, Little M, Boussinesq M: River blindness: a success story under threat. PLoS Med 2006, 3:e371.

52. Brooker S, Kabatereine NB, Gyapong JO, Stothard JR, Utzinger J: Rapid mapping of schistosomiasis and other neglected tropical diseases in the 
context of integrated control programmes in Africa. Parasitology 2009, 1707-1718.

53. Takougang I, Meremikwu M, Wandji S, Yenshu EV, Aripko B, Lamlenn SB, Eka BL, Enyong P, Meli J, Kale O, Remme JH: Rapid assessment method for prevalence and intensity of Loa loa infection. Bull World Health Organ 2002, 80:852-858 [http://www.who.int/bulletin/archives/80\%2811\%29852. pdf].

54. Weil GJ, Lammie PJ, Weiss N: The ICT Filariasis Test: A rapid-format antigen test for diagnosis of bancroftian filariasis. Parasitol Today 1997, 13:401-404.

55. Gyapong JO, Kyelem D, Kleinschmidt I, Agbo K, Ahouandogbo F, Gaba J, Owusu-Banahene G, Sanou S, Sodahlon YK, Biswas G, et al: The use of spatial analysis in mapping the distribution of bancroftian filariasis in four West African countries. Ann Trop Med Parasitol 2002, 96:695-705.

56. Ottesen EA: Lymphatic filariasis: Treatment, control and elimination. Adv Parasitol 2006, 61:395-441.

57. Cairncross $S$, Muller R, Zagaria N: Dracunculiasis (Guinea worm disease) and the eradication initiative. Clin Microbiol Rev 2002, 15:223-246 [http:// cmr.asm.org/cgi/reprint/15/2/223].

58. Ottesen EA, Duke BO, Karam M, Behbehani K: Strategies and tools for the control/elimination of lymphatic filariasis. Bull World Health Organ 1997, 75:491-503 [http://whqlibdoc.who.int/bulletin/1997/Nol75-No6/ bulletin_1997_75\%286\%29_491-503.pdf].

59. Legros D, Ollivier G, Gastellu-Etchegorry M, Paquet C, Burri C, Jannin J, Buscher P: Treatment of human African trypanosomiasis-present situation and needs for research and development. Lancet Infect Dis 2002, 2:437-440

60. Nieuwenhove SV, Betu-Ku-Mesu VK, Diabakana PM, Declercq J, Bilenge CMM: Sleeping sickness resurgence in the DRC: the past decade. Trop Med Int Health 2001, 6:335-341.

61. Moore A, Richer M, Enrile M, Losio E, Roberts J, Levy D: Resurgence of sleeping sickness in Tambura County, Sudan. Am J Trop Med Hyg 1999, 61:315-318 [http://www.ajtmh.org/cgi/reprint/61/2/315.pdf].

62. Simarro PP, Franco JR, Ndongo P, Nguema E, Louis FJ, Jannin J: The elimination of Trypanosoma brucei gambiense sleeping sickness in the focus of Luba, Bioko Island, Equatorial Guinea. Trop Med Int Health 2006 11:636-646.

63. Batchelor NA, Atkinson PM, Gething PW, Picozzi K, Fèvre EM, Kakembo AS, Welburn SC: Spatial predictions of Rhodesian Human African Trypanosomiasis (sleeping sickness) prevalence in Kaberamaido and Dokolo, two newly affected districts of Uganda. PLoS Negl Trop Dis 2009, 3:e563.

64. Berrang Ford $\mathrm{L}$ : Civil conflict and sleeping sickness in Africa in general and Uganda in particular. Conflict and Health 2007, 1:6 [http://www. conflictandhealth.com/content/1/1/6].

65. Cecchi G, Mattioli R: Geospatial datasets and analyses for an environmental approach to African trypanosomiasis. Rome: Food and Agriculture Organization of the United Nations; 2009 [http://www.fao.org/ docrep/012/i0809e/i0809e00.htm].

doi:10.1186/1476-072X-9-57

Cite this article as: Simarro et al:: The Atlas of human African

trypanosomiasis: a contribution to global mapping of neglected tropical diseases. International Journal of Health Geographics 2010 9:57.

\section{Submit your next manuscript to BioMed Central and take full advantage of:}

- Convenient online submission

- Thorough peer review

- No space constraints or color figure charges

- Immediate publication on acceptance

- Inclusion in PubMed, CAS, Scopus and Google Scholar

- Research which is freely available for redistribution

Submit your manuscript at www.biomedcentral.com/submit
Biomed Central 